\title{
Article
}

\section{Vortex Breakdown Control by the Plasma Swirl Injector}

\author{
Gang $\mathrm{Li}^{1,2, *}$, Xi Jiang ${ }^{3}$, Wei Du ${ }^{1,2}$, Jinhu Yang ${ }^{1,2, *} \mathbb{C}$, Cunxi Liu ${ }^{1,2} \mathbb{C}$, Yong Mu ${ }^{1,2}$ and Gang Xu ${ }^{1,2}$ \\ 1 Key Laboratory of Light Duty Gas Turbine, Institute of Engineering Thermophysics, Chinese Academy of \\ Sciences, Beijing 100190, China; duwei@iet.cn (W.D.); liucunxi@iet.cn (C.L.); muyong@iet.cn (Y.M.); \\ xug@iet.cn (G.X.) \\ 2 School of Aeronautics and Astronautics, University of Chinese Academy of Sciences, Beijing 100049, China \\ 3 School of Engineering and Materials Science, Queen Mary University of London, Mile End Road, \\ London E1 4NS, UK; xi.jiang@qmul.ac.uk \\ * Correspondence: ligang@iet.cn (G.L.); yangjinhu@iet.cn (J.Y.)
}

Citation: Li, G.; Jiang, X.; Du, W.; Yang, J.; Liu, C.; Mu, Y.; Xu, G. Vortex Breakdown Control by the Plasma Swirl Injector. Appl. Sci. 2021, 11, 5537. https://doi.org/10.3390/ app11125537

Academic Editor: Mariusz Jasiński

Received: 7 May 2021

Accepted: 7 June 2021

Published: 15 June 2021

Publisher's Note: MDPI stays neutral with regard to jurisdictional claims in published maps and institutional affiliations.

Copyright: (c) 2021 by the authors. Licensee MDPI, Basel, Switzerland. This article is an open access article distributed under the terms and conditions of the Creative Commons Attribution (CC BY) license (https:/ / creativecommons.org/licenses/by/ $4.0 /)$.

\begin{abstract}
Vortex breakdown, observed in swirling flows, is an interesting physical phenomenon relevant to a wide range of engineering applications, including aerodynamics and combustion. The concept of using a plasma swirler to control vortex breakdown was proposed and tested in this study. The effect of plasma actuation on controlling the onset and development of the vortex breakdown was captured by particle image velocimetry. Flowfield measurement results suggested that, by varying the strength of the plasma actuation, the location and size of the vortex breakdown region was controlled effectively. The plasma swirl injector offers a method for optimal control and efficient utilization of vortex breakdown. The method being proposed here may represent an attractive way of controlling vortex breakdown using a small amount of energy input, without a moving or intrusive part.
\end{abstract}

Keywords: vortex break down; plasma swirl injector; dielectric barrier discharge; swirling flow control

\section{Introduction}

As an active flow and combustion control device, the dielectric barrier discharge (DBD) actuator has drawn much attention for its fast response, low power consumption, and simple structure, as described by Roth et al. [1]. The operation of the DBD actuator is purely electric without any moving part, which is attractive to many applications. Recent investigations on plasma actuators have been reviewed by Moreau [2], Corke et al. [3], Wang et al. [4], Kriegseis et al. [5], Leonov et al. [6] and Konstantinidis [7], to name but a few. Flow separation control by the DBD actuator was widely researched. Roupassov et al. [8] observed that the heat released by nanosecond pulse actuation can produce shock waves, where the associated secondary vortex flows disturbed the main flow and caused an efficient transversal momentum transfer into the boundary layer. Flow separation control was investigated experimentally by Little et al. [9] on an airfoil leading edge up to $62 \mathrm{~m} / \mathrm{s}$ with nanosecond pulse plasma actuator. They pointed out that the plasma actuator was similar to an active trip, which can generate coherent spanwise vortices at post stall. Fujii [10] showed that actuation in burst mode was very effective for controlling flow separation at a Reynolds number of $6.3 \times 10^{4}$, where the three features of the flow structure, associated with flow separation control, were emphasized and guidelines for the effective use of DBD actuators were proposed. Meanwhile, the modelling approach of Shyy et al. [11] was adopted by Hasan et al. [12] to simulate the 3D separated flow over a hump model with the inlet velocity of $34.6 \mathrm{~m} / \mathrm{s}$. They demonstrated that the flow separation was completely suppressed with the actuator placed just downstream of the separation point at an applied frequency of $5 \mathrm{kHz}$. Through flowfield measurement by particle image velocimetry (PIV) and a pressure cap over a wing section, Skourides et al. [13] emphasized that the actuation frequency was critical to the control authority of a nanosecond-DBD actuator. Pescini et al. [14] used a micro plasma actuator to suppress flow separation in 
the low-pressure turbine of small engines. They pointed out that the sinus waveforms outperformed other waveforms slightly. Lo et al. [15] tested the effective flow separation control over the rear end of a lorry (1:20 scale) by the plasma actuation with the free stream velocity at $30 \mathrm{~m} / \mathrm{s}$. They found that the shear layer was deflected more downwards due to the actuation. However, the flow characteristics in the wake region was not significantly modified by the actuation and they concluded that no flow control effect was observed in their study. All of these studies demonstrate the wide range of applications of plasma actuation, with further potentials to be explored.

Using ionic wind (which is the airflow induced by electrostatic forces linked to plasma discharge) for local cooling is also an interesting research topic. Go et al. [16] demonstrated that heat transfer was increased by ionic wind through distortion of the boundary layer. Roy and Wang [17] developed the idea of film cooling enhancement by plasma actuator. Through PIV and infrared thermography measurements, Audier et al. [18] found that the actuation deflected the jet toward the wall and delayed its diffusion into the cross flow, and, as a result, the effectiveness of the film cooling was increased. Through numerical simulation, the mechanism of film cooling improvement by plasma actuator was analyzed by Xiao et al. [19]. They found that the counter rotating vortex pairs were weakened by the actuation, which led to less interaction and reduced mixing between the main flow and the jet flow. A pressure sensitive paint technique was adopted by Kim et al. [20] to investigate the effect of DBD actuation on the film cooling effectiveness of a $30^{\circ}$ slot with the mainstream velocity at $10 \mathrm{~m} / \mathrm{s}$. They pointed out that the improvement was not significant and that the actuator configuration should be optimized. Uehara and Takana [21] developed a plasma actuator cooling device in millimeter scale channels with a height of $2.5 \mathrm{~mm}, 10 \mathrm{~mm}$, and $50 \mathrm{~mm}$, without an upper wall. They found that the heat transfer coefficient was inversely proportional to the channel height. However, when the height was $2.5 \mathrm{~mm}$, the heat transfer coefficient was larger than that of the height of $5 \mathrm{~mm}$. They attributed this to the suppression of backward flow which impeded the cooling performance. They were optimistic about the feasibility of the plasma actuator cooling for a confined space. The plasma actuator was also adopted to control noise and vibration. The experiments of Hebrero et al. [22] showed that plasma actuators exhibited the ability to suppress vortex-induced vibration around a rigid circular cylinder. During their experiments the flow velocity was varied between 3 to $4.25 \mathrm{~m} / \mathrm{s}(6000<\operatorname{Re}<8500)$. Yokoyama et al. [23] demonstrated that the plasma actuation was effective in reducing the cavity tone with the acoustic resonances at freestream velocity of $30 \mathrm{~m} / \mathrm{s}$ by introducing streamwise vortices with fine displacement. A new corner-type actuator configuration was designed by Jong et al. [24] to control flow induced noise in a cavity. They demonstrated that the aero-acoustic lock-on was suppressed for freestream velocities below $12.5 \mathrm{~m} / \mathrm{s}$ by the inward-inducing actuator. PIV measurement showed that a secondary circulating flow region was created by the actuation which prevented lock-on. The experimental research of Silva et al. [25] demonstrated that the DBD actuators were able to reduce aerodynamic noise from slats with wind tunnel velocity of $27.4 \mathrm{~m} / \mathrm{s}$. They also pointed out that the control authority of the actuators tested was still poor for real flight conditions, and that further research is needed to produce more efficient plasma actuators. The control effects of the plasma actuation on the flow around an oscillating plate was investigated by Sato et al. [26]. They pointed out that it was possible for the DBD actuator to control the lift with a mechanism similar to that of an insect. They found that the appropriate adjustment of the driving time played an important role in lift enhancement. Motta et al. [27] numerically assessed the effectiveness of plasma actuators for load alleviation on a compressor cascade. They demonstrated that it was effective to alter the blade loading by proper triggering of the pressure and suction side of the actuation. A number of studies have been carried out to enhance the performance of DBD actuators, such as the shape of the serpentine actuator [28], wire type electrode [29], microfabricated DBD actuator [30], sawtooth electrode [31], and DBD active grid [32]. 
Vortex breakdown (VB) observed in swirling flows is an interesting physical phenomenon relevant to a wide range of engineering applications such as aerodynamics (delta wing, and blade tip leakage flow) and combustion. Peckham and Atkinson [33] first reported vortex breakdown on a delta wing at a high angle of attack. The vortex lines near the edges of the wing experience a sudden change in shape when the angle of attack is increased. This phenomenon is referred to as vortex breakdown. Sarpkaya [34] observed three types of vortex breakdown: double helix, spiral, and axisymmetric (bubble). Bubble breakdown is characterized by a stagnation point on the swirl axis, followed by an abrupt expansion of the centerline to form an envelope of recirculating fluid [35]. Leibovich [36] defined vortex breakdown as "a disturbance characterized by the formation of an internal stagnation point on the vortex axis, followed by a reversed flow in a region of limited axial extension". Several theories were proposed to explain the process of vortex breakdown, such as critical state or wave phenomena theory [37], boundary layer separation or flow stagnation [38], and hydrodynamic instability [39]. Shtern [40] recommended the swirldecay mechanism (SDM) as a simple physical reason for the vortex breakdown occurrence, and also pointed out that SDM indicated efficient means for vortex breakdown control. The flow and boundary conditions have a strong effect on the breakdown process. Sarpkaya [34] observed a periodic transition between bubble-type and spiral-type depending on the flow and boundary conditions. Aithaus et al. [41] observed the transition from bubble-type and spiral-type, both in experiments and numerical simulations, and proposed a feedback model for the initiation and development of the bubble-type breakdown. It is of practical important to study methods of controlling VB, so that it can be enhanced when it is beneficial and weakened when it is detrimental. The main techniques employed to control VB include temperature gradient (Herrada and Shtern [42]), shape modification (Srigrarom and Kurosaka [43]), blowing (Schmucker and Gersten [44], Gutmark and Guillot [45]), rotation of the end walls (Mununga et al. [46]), the addition of near-axis swirl (Husain et al. [47]), and energy deposition (Zheltovodov et al. [48]). Mitchell and Delery reviewed the early research on VB control in detail [49], while the developments in this area are continuously evolving.

Although vortex breakdown should be suppressed on a delta wing, it is commonly adopted in combustion and acts as a stabilizer to enhance reactant mixing and stabilization of the flame by recirculating hot gases into its base. Inspired by the idea of accelerating the same fluid particles continuously, we designed a plasma swirler with the electrode placed in the streamwise direction [50]. The plasma swirl injector is effective in diffusion and premixed flame control [51,52], and can be integrated into a low swirl injector to control the flame lift off height accurately $[53,54]$. The electrode of the plasma swirler was optimized as a helical shape to enhance its performance [55]. In this study, the concept of using the plasma swirler to control vortex breakdown was proposed and tested. A plasma swirler with a helical shape was adopted to control the vortex breakdown. The plasma actuation, in affecting the onset and development of the vortex breakdown, was captured and analyzed.

\section{Layout of the Experimental Setup}

The plasma swirl injector with a helical-shaped electrode was adopted for this research. Figure 1 shows the sketch and the photograph of the plasma swirl injector used in the experiment. Design parameters and advantages of the helical shape electrode were discussed previously [55]. The length and inner diameter of the quartz glass tube are $100 \mathrm{~mm}$ and $36 \mathrm{~mm}$, respectively. In this study, the actuator was further optimized. The electrodes were arranged perpendicular to the blades at the inlet of the electrode. Compared to that of $170 \mathrm{~mm}$ in the earlier study [55], the helix pitch was shortened to $100 \mathrm{~mm}$, which means the electrode was longer and more plasma could be generated at the same voltage. The length of the electrode was approximately $130 \mathrm{~mm}$. The activated and grounded electrodes were stuck to the inside and outside wall of the injector with a width of $2.5 \mathrm{~mm}$ and $7.5 \mathrm{~mm}$, respectively. 


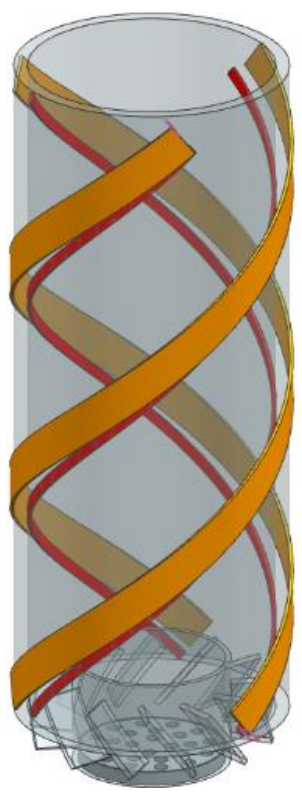

(a) Sketch of the plasma swirler

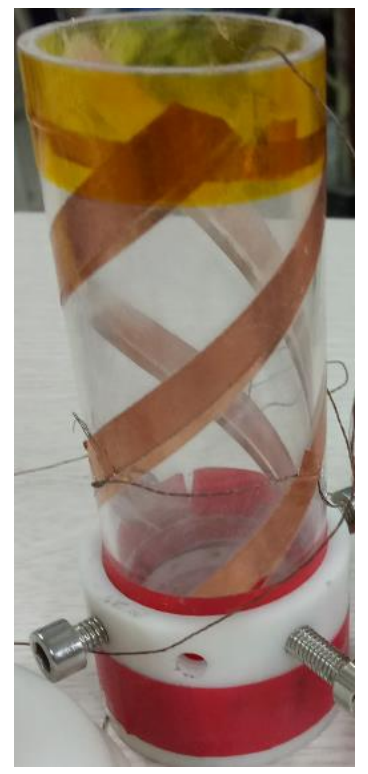

(b) Photograph of the plasma swirler

Figure 1. Sketch and photograph of plasma swirler with helical shape electrodes.

In the experiment, air volumetric flow was $175 \mathrm{l} / \mathrm{min}$ and the corresponding bulk flow velocity in the injector was approximately $3 \mathrm{~m} / \mathrm{s}$. The power inputs of the plasma generator were approximately $31 \sim 76 \mathrm{~W}$ and the electrodes on the inner wall were activated with a peak-to-peak amplitude of $12 \sim 21 \mathrm{kV}$. Parameters of the five test cases are listed in Table 1.

Table 1. The five test cases and their experimental conditions.

\begin{tabular}{cccccc}
\hline Test Case & $\begin{array}{c}\text { Actuator } \\
\text { Status }\end{array}$ & $\begin{array}{c}\text { Waveform } \\
\text { Type }\end{array}$ & $\begin{array}{c}\text { Voltage } \\
\text { Amplitude } \\
\mathbf{( k V )}\end{array}$ & $\begin{array}{c}\text { Voltage } \\
\text { Frequency } \\
(\mathbf{k H z})\end{array}$ & $\begin{array}{c}\text { Power } \\
\text { Inputs } \\
\text { (W) }\end{array}$ \\
\hline 1 & OFF & - & - & - & - \\
2 & ON & Sinusoidal & 12 & 9 & 31 \\
3 & ON & Sinusoidal & 15 & 9 & 45 \\
4 & ON & Sinusoidal & 18 & 9 & 60 \\
5 & ON & Sinusoidal & 21 & 9 & 76 \\
\hline
\end{tabular}

Figure 2 shows the schematic of the experimental setup in this research. The flowfields of the five test cases were captured by 2D PIV, manufactured by Lavision (Gottingen, Genmany) [55]. A screw compressor supplied compressed air, which was then settled into two tanks of $1.2 \mathrm{~m}^{3}$. A small wind tunnel, manufactured by 3D printing, was installed on a displacement device. Through the bottom inlet of the wind tunnel, air flowed into the settling chamber, in which two layers of honeycomb were used to improve flow uniformity. A contraction section, with an area ratio of 6:1, was used to further improve the flow quality. A mass flowmeter was utilized to regulate and measure the flow rate. 


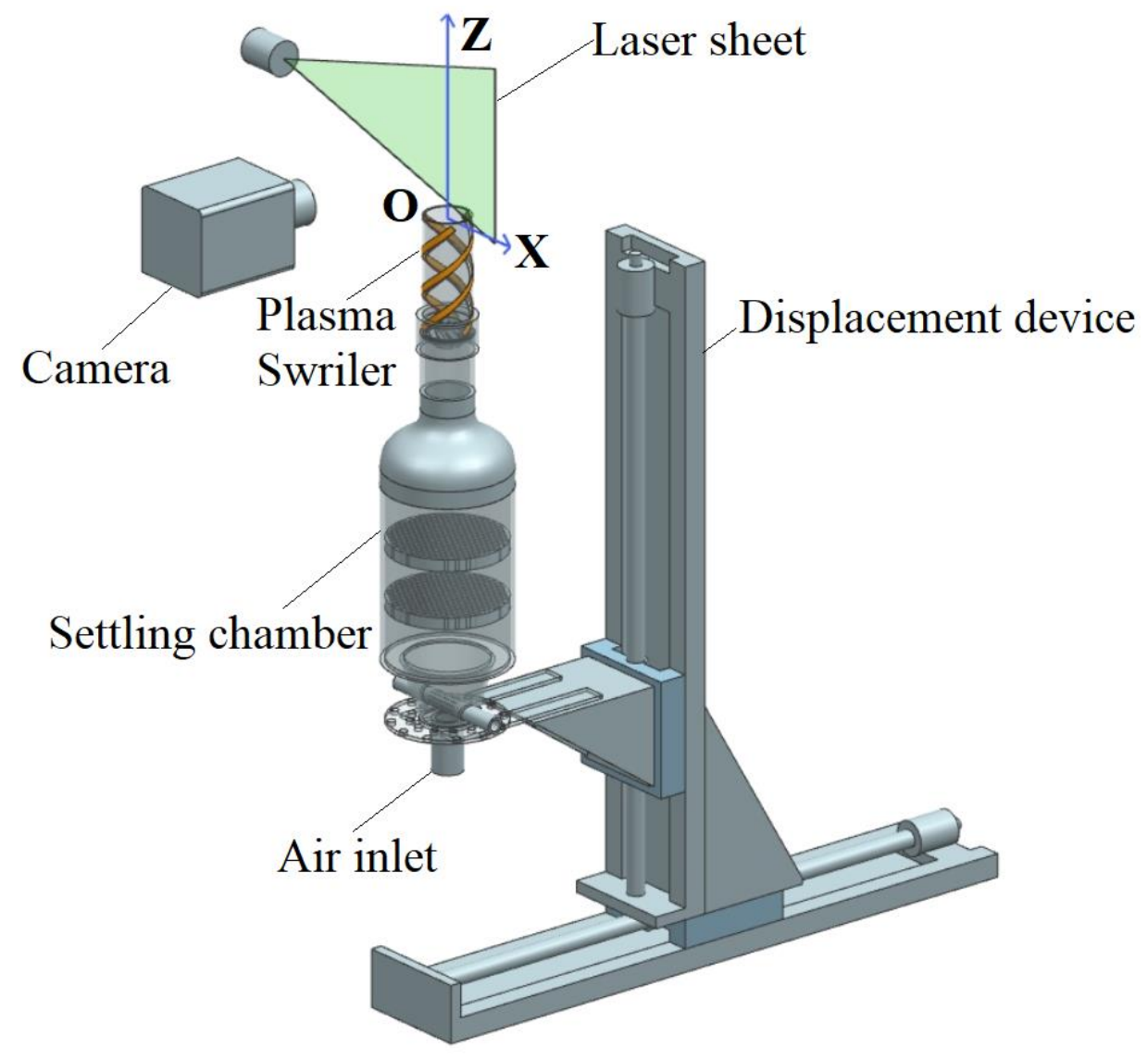

Figure 2. Schematic of the experimental setup.

\section{Results and Discussion}

The flowfield, obtained by 2D PIV, provides information about the presence and location of vortex breakdown. The leading edge of the VB could be identified by a stagnation point along the centerline. Contours of axial velocity in the centerline plane (the laser plane in Figure 2) were captured for each case to provide a global quantitative and qualitative depiction of the flowfield. Figure 3a-e, from 2D PIV measurements, show the axial velocity magnitude contours and vectors in the $\mathrm{XZ}$ plane for the five conditions tested, with a bulk velocity of $3 \mathrm{~m} / \mathrm{s}$ and a corresponding Reynolds number of 7171 based on the injector diameter. The approximate exit of the injector was at $Z=-2 \mathrm{~mm}$. Location of a breakdown zone can be identified by the negative axial velocity and recirculating flow.

Generally, the axial velocity distribution of a low swirl flowfield accords with the normal distribution of this type of jet flow, but the maximum axial velocity moves away from the axis due to the effect of the mesh plate of the low swirl injector, forming a double peak velocity profile as shown in Figure 3a. The velocity in the annular region is higher because of the significant downward momentum of the flow in this region, compared with the flow in the central region. The central low velocity region, as well as the shear layer between the non-swirling core and swirling annulus, are critical for flame stabilization. When the swirl jet flows out of the low swirl injector, the low pressure in the center region of the swirl flow recovers gradually, which leads to the generation of the reverse pressure gradient in the axial direction. Without plasma actuation, the axial pressure gradient is not large enough to cause reverse flow. At $12 \mathrm{kV}$, the decrease of axial velocity near the central region can be observed, where the central low velocity region swells slightly and the degree of flow expansion increases as well, but the actuation is not strong enough to cause flow reversal and no vortex breakdown is observed, as shown in Figure $3 \mathrm{~b}$. Increasing the strength of actuation to $15 \mathrm{kV}$ resulted in the generation of a stagnation point as a result of the reverse pressure gradient increase and the decrease of the axial velocity. Although the 
low velocity region and the degree of flow expansion remained almost unchanged, flow reversal occurred in a small region and the onset of the breakdown bubble was observed in regions close to the centerline at around $Z=15 \mathrm{~mm}$, as shown in Figure 3c. Bubbletype breakdown is characterized by a nearly axisymmetric region of reversed flow, with a stagnation point at the forward end. As the actuation voltage was further increased to $18 \mathrm{kV}$, the stable bubble-type vortex breakdown was observed to migrate upstream and was fully established with a forward stagnation point at about $Z=1 \mathrm{~mm}$ and a backward stagnation point at $Z=36 \mathrm{~mm}$, as shown in Figure 3d. Its outer shape was nearly axisymmetric and can be visualized as a bubble. Due to the existence of the vortex, the outer boundary of the jet expanded immediately after it flowed out of the injector. As the strength of actuation was increased to $21 \mathrm{kV}$, the breakdown zone grew further due to the enhanced backflow, and its nose becomes less pointed and wider, as shown in Figure 3e. The breakdown zone shifted upstream with the forward stagnation point penetrating into the injector, but the position of the backward stagnation point changed very slightly compared to that of $18 \mathrm{kV}$. This shows that the actuation does not significantly affect the overall location of the bubble, although it enhances its size. The interior structures of the bubble were nearly the same for the two cases.

Based on these results, it can be concluded that the $15 \mathrm{kV}$ actuation is strong enough to trigger the onset of vortex breakdown with a relatively low power input. The upstream stagnation point and the center of the breakdown bubble migrated upstream with increasing actuation strength, whereas the downstream stagnation point maintained a constant position. Bubble-type breakdown was stable under these conditions. The overall shape of the bubble did not change significantly with the strength of actuation increased from $18 \mathrm{kV}$ to $21 \mathrm{kV}$. The interior structures of the bubble were nearly the same, containing one major cell or vortex ring. The gross exterior appearance of the bubble was axisymmetric, while the internal structure was asymmetric to some extent. The length-to-diameter ratio of the bubble was approximately 1.61 and 1.48 , with the maximum diameter occurring at approximately $\mathrm{Z}=20 \mathrm{~mm}$ and $\mathrm{Z}=18 \mathrm{~mm}$ for $18 \mathrm{kV}$ and $20 \mathrm{kV}$, respectively. With the increase of the excitation voltage, the asymmetry between the two different sides of the vortex ring increased, but the number of vortex rings did not increase.
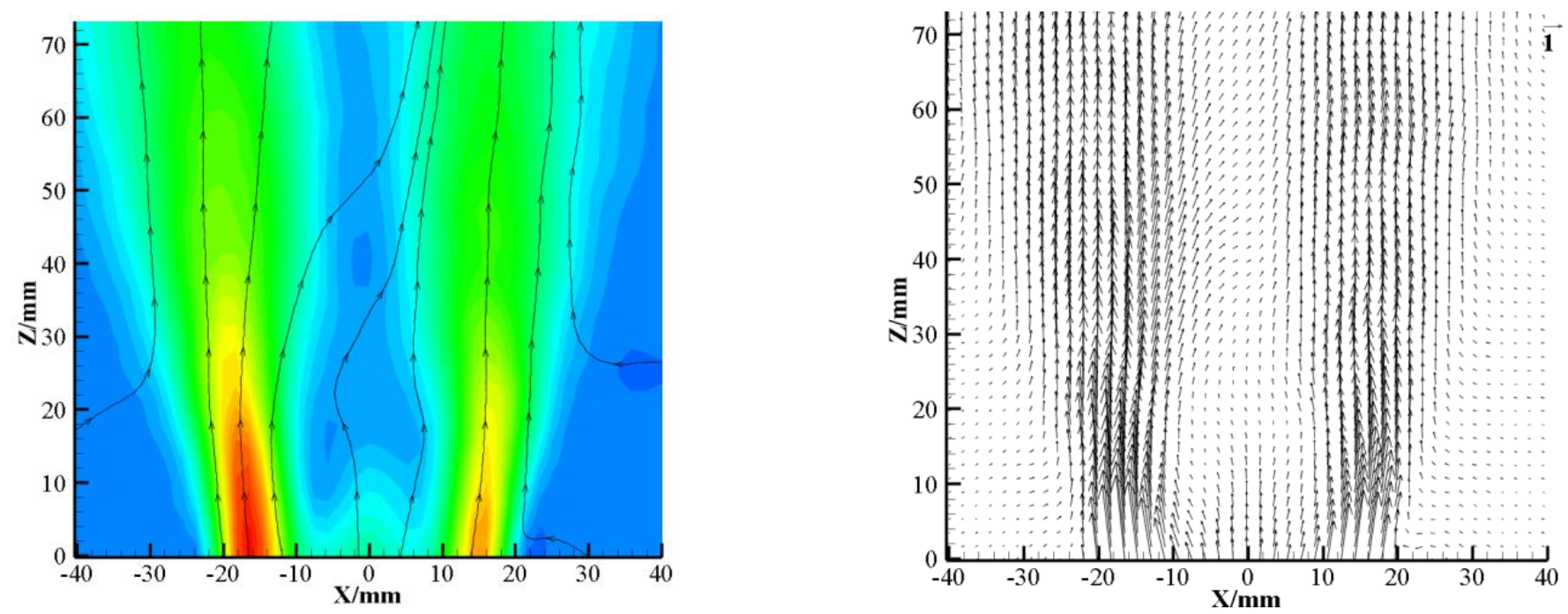

(a) DBD actuation off

Figure 3. Cont. 

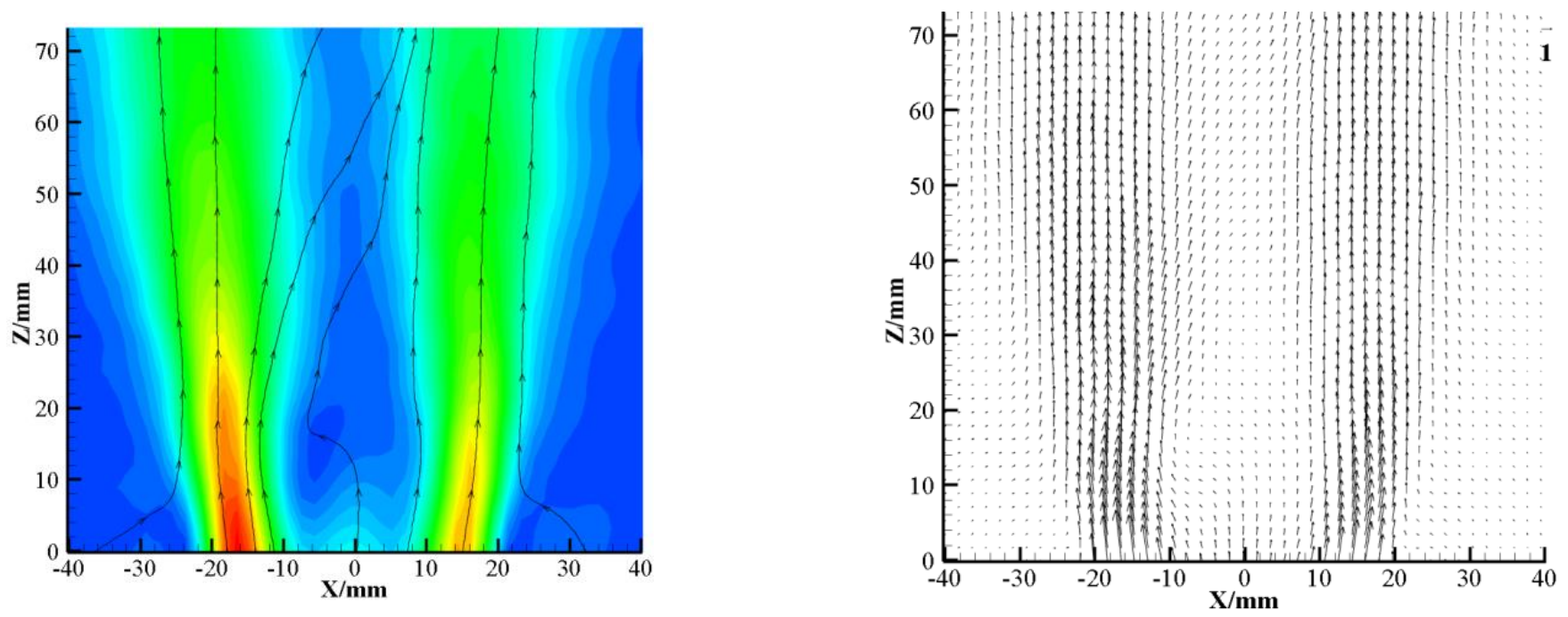

(b) DBD actuation on $(12 \mathrm{kV})$
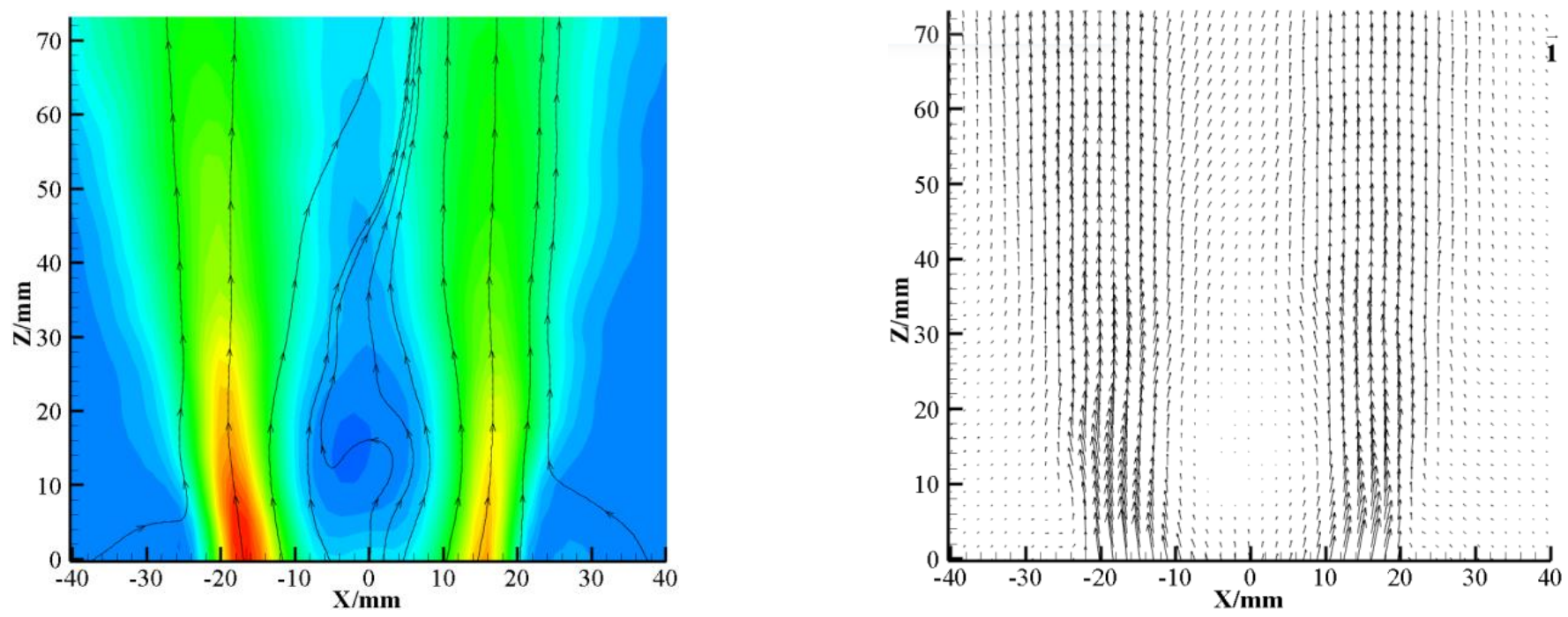

(c) DBD actuation on $(15 \mathrm{kV})$
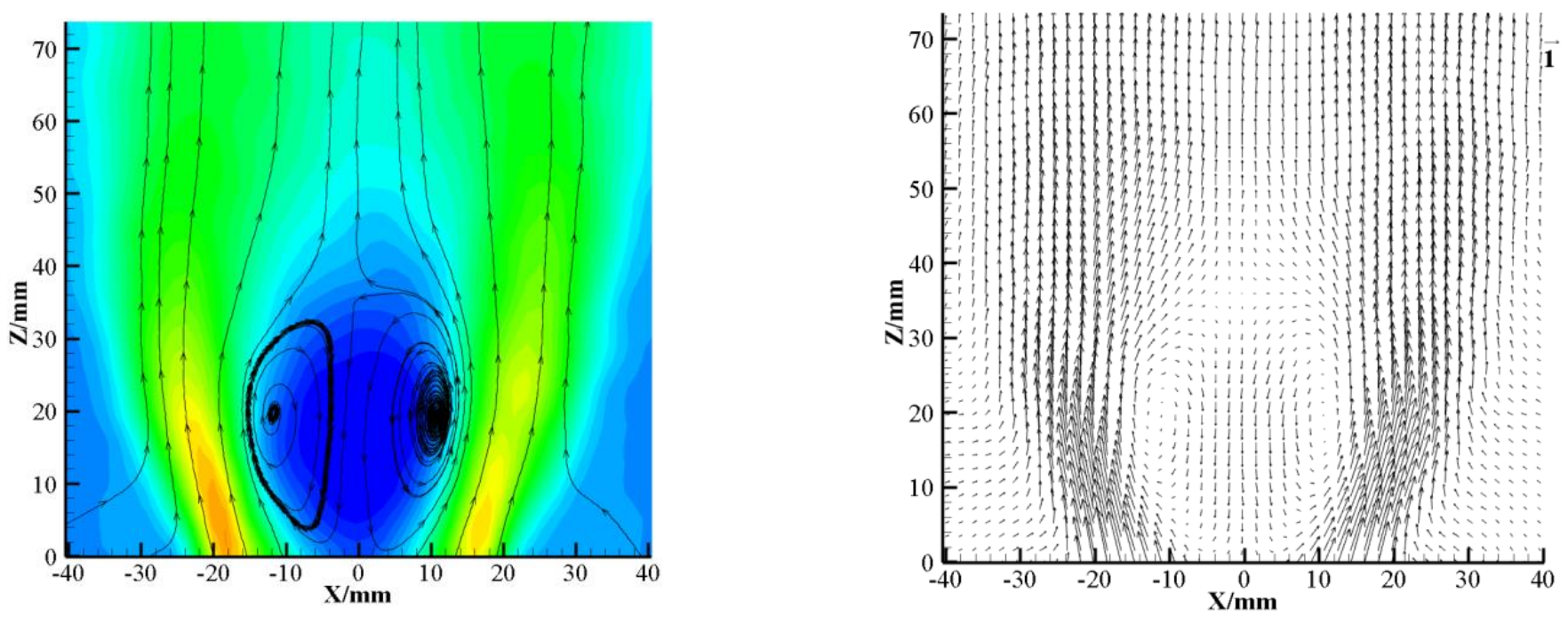

(d) DBD actuation on $(18 \mathrm{kV})$

Figure 3. Cont. 

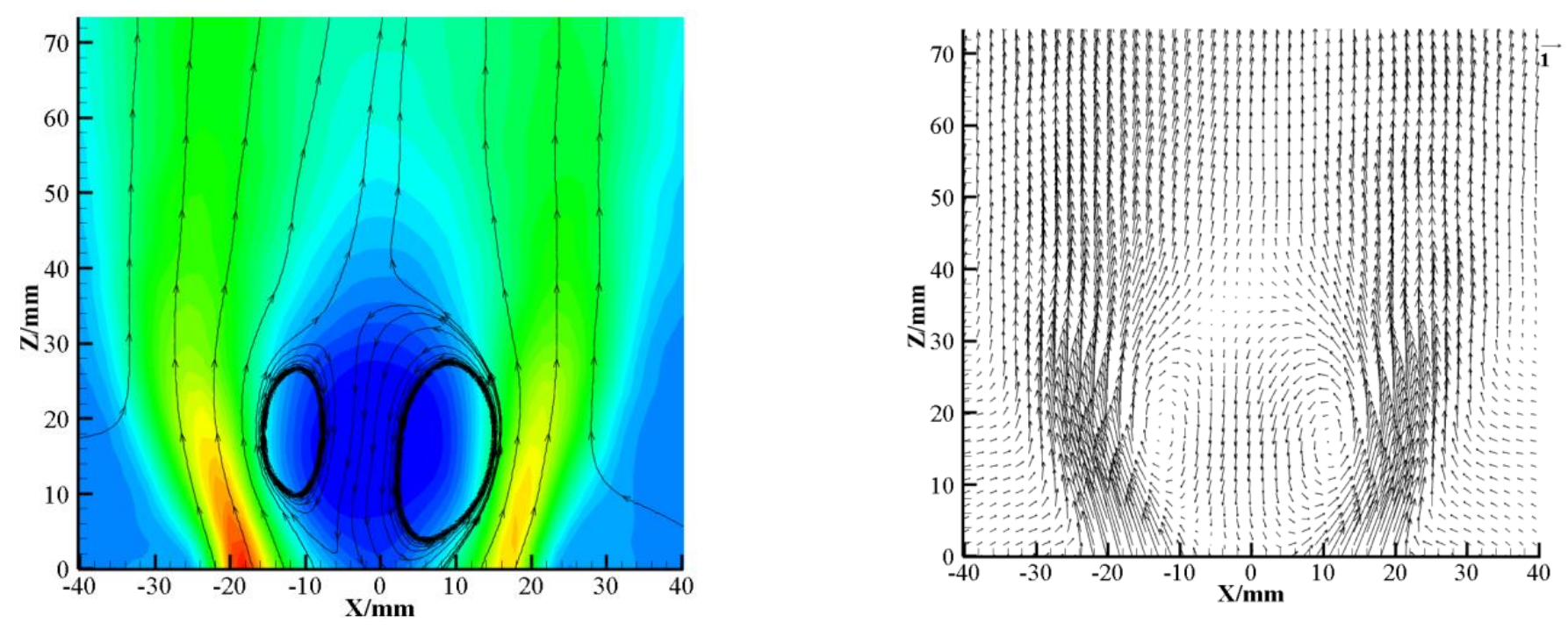

(e) DBD actuation on $(21 \mathrm{kV})$

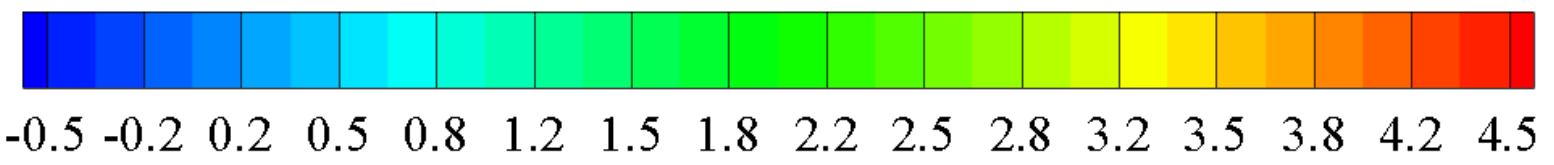

Figure 3. Contours of mean axial velocity magnitude, streamlines, and vectors (left: magnitude contours and streamlines; and right: vectors) in the XZ plane with bulk velocity of $3 \mathrm{~m} / \mathrm{s}$.

Figure 4 summarizes the axial velocity profiles along the centerline $(X=0 \mathrm{~mm})$ for the five cases with voltages ranging from $0 \mathrm{kV}$ to $21 \mathrm{kV}$. The figure shows that the gradual increase of voltage resulted in a gradual deceleration of the axial velocity along the centerline and a gradual appearance and upstream movement of the vortex breakdown. Without plasma actuation, the axial velocity at the injector outlet was $1.2 \mathrm{~m} / \mathrm{s}$. Moving downstream, the axial velocity linearly decreased to $Z=22 \mathrm{~mm}$, achieving a lower value of $0.23 \mathrm{~m} / \mathrm{s}$. Then a velocity plateau appeared, which means the velocity remained essentially unchanged. Applying the $12 \mathrm{kV}$ excitation, the axial velocity distribution in the $\mathrm{Z}=0 \sim 20 \mathrm{~mm}$ zone moved down slightly, and the injector outlet velocity dropped to $0.99 \mathrm{~m} / \mathrm{s}$, but the overall change was not obvious, and the velocity plateau positions coincided. When the excitation was increased to $15 \mathrm{kV}$, the injector outlet velocity decreased to $0.62 \mathrm{~m} / \mathrm{s}$, and the axial velocity, in the range of $Z=0 \sim 20 \mathrm{~mm}$, decreased appreciably. However, because the vortex breakdown zone was very small and did not pass through the jet centerline, the stagnation point and recirculation zone cannot be captured in the axial velocity distribution along the centerline. When the excitation was increased to $18 \mathrm{kV}$, the injector outlet velocity decreased to $-0.1 \mathrm{~m} / \mathrm{s}$, and an obvious backflow zone appeared in the region of $Z=0 \sim 40 \mathrm{~mm}$. When the excitation was further increased to $21 \mathrm{kV}$, the overall velocity distribution changed slightly. Although the magnitude of the reverse velocity increased slightly, the length of the vortex zone and the position of the stagnation point remained basically unchanged. The velocity increased linearly after it reached the minimum value at $Z=22 \mathrm{~mm}$, and no velocity plateau could be observed.

Figure 5 shows the axial velocity magnitude contours and streamlines with a bulk velocity of $5.7 \mathrm{~m} / \mathrm{s}$. The plasma actuation-induced bubble-type vortex breakdown was still obvious, while the interior structures of the bubble contained one major cell as well. However, the size of the bubble decreased, which indicates that the effect of plasma actuation decreases with the increase of flow rate. More work is needed to establish the correlations between the effectiveness of plasma actuation, the jet inlet velocity, and other parameters, in order to gain a full understanding. Further research is needed to enhance the plasma flow control authority to put this method into engineering applications, including full-scale applications. 


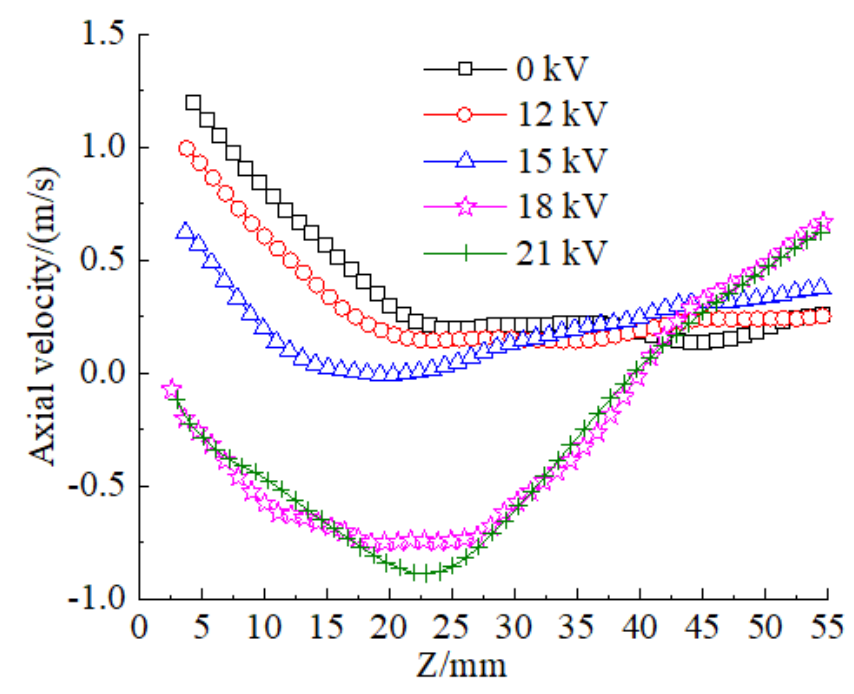

Figure 4. Profiles of the mean axial velocity.

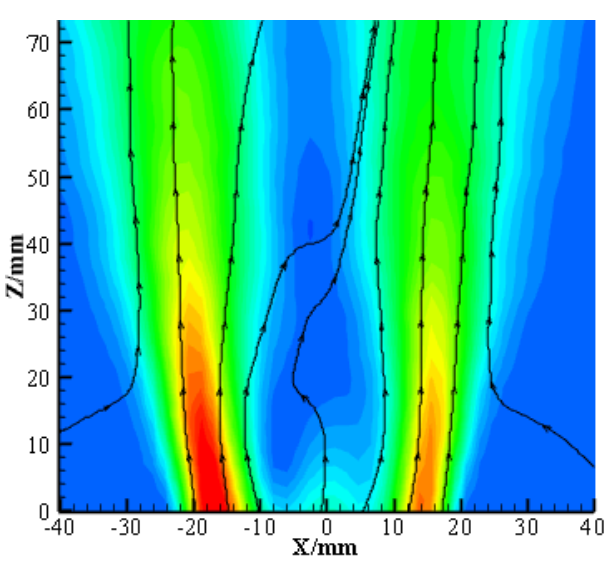

(a) Actuation off
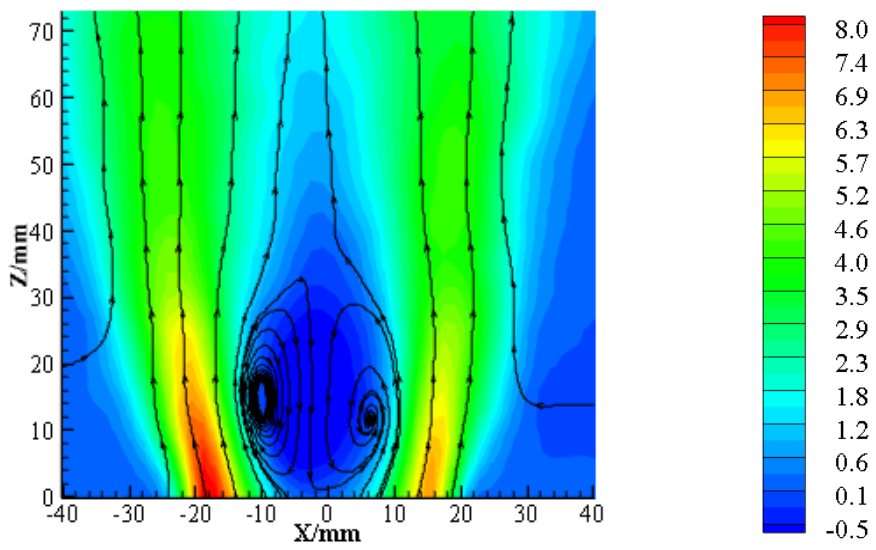

(b) Actuation on

Figure 5. Contours of mean axial velocity magnitude and streamlinesin the XZ plane with bulk velocity of $5.7 \mathrm{~m} / \mathrm{s}$.

\section{Conclusions}

In this study, the concept of using the plasma swirler to control vortex breakdown was proposed and tested. It was observed in the experiments that, by varying the strength of the plasma actuation, the vortex breakdown region could be effectively controlled. The plasma swirler, as a nonintrusive, no-moving-part method of controlling vortex breakdown, was demonstrated experimentally. Flowfield measurement demonstrated that the plasma actuation was both effective and efficient in controlling the development of vortex breakdown. Experimental results showed that the $15 \mathrm{kV}$ actuation was strong enough to trigger the onset of vortex breakdown. The overall shape of the bubble did not change significantly when the strength of actuation increased from $18 \mathrm{kV}$ to $21 \mathrm{kV}$. The interior structures of the bubble were nearly the same, containing one major cell or vortex ring. Without involving moving parts or mass adding, the plasma actuation offers great flexibility in flow and combustion control. It offers a choice for fundamental research of vortex breakdown phenomena, where the actuation strength and frequency can be varied and controlled easily. Further research is needed to enhance the plasma flow control authority to put this method into engineering applications.

Author Contributions: Conceptualization, G.L.; validation, X.J., W.D. and J.Y.; formal analysis, C.L.; data curation, Y.M.; writing—original draft preparation, G.L.; writing—review and editing, X.J.; supervision, G.X. All authors have read and agreed to the published version of the manuscript. 
Funding: This research received no external funding.

Acknowledgments: The research was supported by the National Natural Science Foundation of China (Grant No. 51676188) and the National Youth Natural Science Foundation of China (Grant No. 51706224), which are gratefully acknowledged.

Conflicts of Interest: The authors declare no conflict of interest.

\section{References}

1. Roth, J.R.; Sherman, D.M.; Wilkinson, P.S. Electrohydrodynamic flow control with a glow-discharge surface plasma. AIAA J. 2000, 38, 1166-1172. [CrossRef]

2. Moreau, E. Airflow control by non-thermal plasma actuators. J. Phys. D Appl. Phys. 2007, 40, 605-636. [CrossRef]

3. Corke, T.C.; Enloe, C.L.; Wilkinson, S.P. Dielectric Barrier Discharge Plasma Actuators for Flow Control. Annu. Rev. Fluid Mech. 2010, 42, 505-529. [CrossRef]

4. Wang, J.J.; Choi, K.S.; Feng, L.H.; Timothy, D.W. Richard, Recent developments in DBD plasma flow control. Prog. Aerosp. Sci. 2013, 62, 52-78. [CrossRef]

5. Kriegseis, J.; Simon, B.; Grundmann, S. Towards in-flight applications? A review on dielectric barrier discharge-based boundarylayer control. Appl. Mech. Rev. 2016, 68, 020802. [CrossRef]

6. Leonov, S.B.; Adamovich, I.V.; Soloviev, V.R. Dynamics of near-surface electric discharges and mechanisms of their interaction with the airflow. Plasma Sources Sci. Technol. 2016, 25, 063001. [CrossRef]

7. Konstantinidis, E. Active Control of Bluff-Body Flows Using Plasma Actuators. Actuators 2019, 8, 66. [CrossRef]

8. Roupassov, D.V.; Nikipelov, A.A.; Nudnova, M.M.; Starikovskii, A.Y. Flow Separation Control by Plasma Actuator with Nanosecond Pulsed-Periodic Discharge. AIAA J. 2009, 47, 168-185. [CrossRef]

9. Little, J.; Takashima, K.; Nishihara, M.; Adamovich, I.; Samimy, M. Separation Control with Nanosecond-Pulse-Driven Dielectric Barrier Discharge Plasma Actuators. AIAA J. 2012, 50, 350-365. [CrossRef]

10. Fujii, K. Three Flow Features behind the Flow Control Authority of DBD Plasma Actuator: Result of High-Fidelity Simulations and the Related Experiments. Appl. Sci. 2018, 8, 546. [CrossRef]

11. Shyy, W.; Jayaraman, B.; Andersson, A. Modeling of glow discharge-induced fluid dynamics. J. Appl. Phys. 2002, 92, 6434-6443. [CrossRef]

12. Hasan, M.; Atkinson, M. Investigation of a Dielectric Barrier Discharge Plasma Actuator to Control Turbulent Boundary Layer Separation. Appl. Sci. 2020, 10, 1911. [CrossRef]

13. Skourides, C.; Nyfantis, D.; Leyland, P.; Bosse, H.; Ott, P. Mechanisms of Control Authority by Nanosecond Pulsed Dielectric Barrier Discharge Actuators on Flow Separation. Appl. Sci. 2019, 9, 2989. [CrossRef]

14. Pescini, E.; de Giorgi, M.G.; Suma, A.; Francioso, L.; Ficarella, A. Separation control by a microfabricated SDBD plasma actuator for small engine turbine applications: Influence of the excitation waveform. Aerosp. Sci. Technol. 2018, 76, 442-454. [CrossRef]

15. Lo, K.-H.; Sriram, R.; Kontis, K. Wake flow characteristics over an articulated lorry model with/without AC-DBD plasma actuation. Appl. Sci. 2019, 9, 2426. [CrossRef]

16. Go, D.B.; Garimella, S.V.; Fisher, T.S.; Mongia, R.K. Ionic winds for locally enhanced cooling. J. Appl. Phys. 2007, 102, 053302. [CrossRef]

17. Roy, S.; Wang, C.-C. Plasma actuated heat transfer. Appl. Phys. Lett. 2008, 92, 231501. [CrossRef]

18. Audier, P.; Fenot, M.; Benard, N.; Moreau, E. Film cooling effectiveness enhancement using surface dielectric barrier discharge plasma actuator. Int. J. Heat Fluid Flow 2016, 62, 247-257. [CrossRef]

19. Xiao, Y.; Dai, S.; He, L.; Jin, T.; Zhang, Q.; Hou, P. Investigation of film cooling from cylindrical hole with plasma actuator on flat plate. Heat Mass Transf. 2016, 52, 1571-1583. [CrossRef]

20. Kim, Y.J.; Kim, G.M.; Shin, Y.; Kwak, J.S. Experimental Investigation on the Effects of DBD Plasma on the Film Cooling Effectiveness of a 30-Degree Slot. Appl. Sci. 2017, 7, 633. [CrossRef]

21. Uehara, S.; Takana, H. Surface cooling by dielectric barrier discharge plasma actuator in confinement channel. J. Electrost. 2020, 104, 103417. [CrossRef]

22. Hebrero, F.C.; Adamo, J.D.; Sosa, R.; Artana, G. Vortex induced vibrations suppression for a cylinder with plasma actuators. J. Sound Vib. 2020, 468, 115121. [CrossRef]

23. Yokoyama, H.; Tanimoto, I.; Iida, A. Experimental Tests and Aeroacoustic Simulations of the Control of Cavity Tone by Plasma Actuators. Appl. Sci. 2017, 7, 790. [CrossRef]

24. de Jong, A.; Bijl, H. Corner-type plasma actuators for cavity flow-induced noise control. AIAA J. 2014, 52, 33-42. [CrossRef]

25. da Silva, G.P.G.; Eguea, J.P.; Croce, J.A.G.; Catalano, M.F. Slat aerodynamic noise reduction using dielectric barrier discharge plasma actuators. Aerosp. Sci. Technol. 2020, 97, 105642. [CrossRef]

26. Sato, S.; Yokoyama, H.; Iida, A. Control of Flow around an Oscillating Plate for Lift Enhancement by Plasma Actuators. Appl. Sci. 2019, 9, 776. [CrossRef]

27. Motta, V.; Malzacher, L.; Peitsch, D. Numerical Assessment of Virtual Control Surfaces for Load Alleviation on Compressor Blades. Appl. Sci. 2018, 8, 125. [CrossRef] 
28. Roy, S.; Wang, C.-C. Bulk flow modification with horseshoe and serpentine plasma actuators. J. Phys. D Appl. Phys. 2008, 42, 032004. [CrossRef]

29. Hoskinson, A.R.; Hershkowitz, N.; Ashpis, D.E. Force measurements of single and double barrier DBD plasma actuators in quiescent air. J. Phys. D Appl. Phys. 2008, 41, 245209. [CrossRef]

30. Pescini, E.; Francioso, L.; De Giorgi, M.G.; Ficarella, A. Investigation of a micro dielectric barrier discharge plasma actuator for regional aircraft active flow control. IEEE Trans. Plasma Sci. 2015, 43, 3668-3680. [CrossRef]

31. Moreau, E.; Cazour, J.; Benard, N. Influence of the air-exposed active electrode shape on the electrical, optical and mechanical characteristics of a surface dielectric barrier discharge plasma actuator. J. Electrost. 2018, 93, 146-153. [CrossRef]

32. Benard, N.; Audier, P.; Moreau, E.; Takashima, K.; Mizuno, A. Active plasma grid for on-demand airflow mixing increase J. Electrost. 2017, 88, 15-23. [CrossRef]

33. Peckham, D.H.; Atkinson, S.A. Preliminary Results of Low Speed Wind Tunnel Test on a Ghotic Wing of Aspect Ratio 1.0; British Aeronautical Research Council: London, UK, 1957.

34. Sarpkaya, T. On stationary and travelling vortex breakdowns. J. Fluid Mech. 1971, 45, 545-559. [CrossRef]

35. Sarpkaya, T. Vortex Breakdown in Swirling Conical Flows. AIAA J. 1971, 9, 1792-1799. [CrossRef]

36. Leibovich, S. The Structure of Vortex Breakdown. Annu. Rev. Fluid Mech. 1978, 10, 221-246. [CrossRef]

37. Benjamin, T.B. Theory of the vortex breakdown phenomenon. J. Fluid Mech. 1962, 14, 593-629. [CrossRef]

38. Gartshore, I.S. Recent Work in Swirling Incompressible Flow; Report LR-343; National Research Council Canada: Ottawa, OT, Canada, 1962.

39. Leibovich, S.; Stewartson, K. A sufficient condition for the instability of columnar vortices. J. Fluid Mech. 1983, 126, 335-356. [CrossRef]

40. Shtern, V. Cellular Flows; Cambridge University Press: New York, NY, USA, 2018.

41. Althaus, W.; Krause, E.; Hofhaus, J.; Weimer, M. Vortex breakdown: Transition between bubble- and spiral-type breakdown. Meccanica 1994, 29, 373-382. [CrossRef]

42. Herrada, M.A.; Shtern, V. Control of vortex breakdown by temperature gradients. Phys. Fluids 2003, 15, 3468-3477. [CrossRef]

43. Srigrarom, S.; Kurosaka, M. Shaping of delta-wing planform to suppress vortex breakdown. AIAA J. 2012, 38, 183-186. [CrossRef]

44. Schmucker, A.; Gersten, K. Vortex breakdown and its control on delta wings. Fluid Dyn. Res. 1998, 3, 268. [CrossRef]

45. Gutmark, E.J.; Guillot, S.A. Control of vortex breakdown over highly swept wings. AIAA J. 2005, 43, 2065-2069. [CrossRef]

46. Mununga, L.; Jacono, D.L.; Sorensen, J.N.; Leweke, T.; Thompson, M.C.; Hourigan, K. Control of confined vortex breakdown with partial rotating lids. J. Fluid Mech. 2014, 738, 5-33. [CrossRef]

47. Husain, H.S.; Shtern, V.; Hussain, F. Control of vortex breakdown by addition of near-axis swirl. Phys. Fluids 2003, 15, 271-279. [CrossRef]

48. Zheltovodov, A.; Pimonov, E.; Knight, D. Supersonic Vortex Breakdown Control by Energy Deposition. In Proceedings of the 43rd AIAA Aerospace Sciences Meeting and Exhibit, Reno, NV, USA, 10-13 January 2005; p. 1048.

49. Mitchell, A.M.; Delery, J. Research into vortex breakdown control. Prog. Aerosp. Sci. 2001, 37, 385-418. [CrossRef]

50. Li, G.; Jiang, X. Effects of electrical parameters on the performance of a plasma swirler. Phys. Scr. 2019, 94, 095601. [CrossRef]

51. Li, G.; Shao, W.; Xu, Y.; Hu, H.; Liu, Y.; Nie, C.; Zhu, J. Swirl diffusion flame control by the plasma swirler. Sci. China Ser. E Technol. Sci. 2011, 54, 1820-1825. [CrossRef]

52. Li, G.; Jiang, X.; Zhao, Y.; Liu, C.; Chen, Q.; Xu, G.; Liu, F. Jet flow and premixed jet flame control by plasma swirler. Phys. Lett. A 2017, 381, 1158-1162. [CrossRef]

53. Li, G.; Jiang, X.; Zhu, J.; Yang, J.; Liu, C.; Mu, Y.; Xu, G. Combustion control using a lobed swirl injector and a plasma swirler. Appl. Therm. Eng. 2019, 152, 92-102. [CrossRef]

54. Li, G.; Jiang, X.; Chen, Q.; Wang, Z. Flame lift-off height control by a combined vane-plasma swirler. J. Phys. D Appl. Phys. 2018, 51, 345205. [CrossRef]

55. Li, G.; Jiang, X.; Jiang, L.; Lei, Z.; Zhu, J.; Mu, Y.; Xu, G. Design and experimental evaluation of a plasma swirler with helical shaped actuators. Sens. Actuators A Phys. 2020, 315, 112250. [CrossRef] 